\title{
Reductions in Police-reported Injuries Associated with Michigan's Safety Belt Law
}

\author{
Fredrick M. Streff, Alexander C. Wagenaar, and Robert H. Schultz
}

\begin{abstract}
This research measured the effects of Michigan's compulsory safety belt use law on traffic crashes and injuries of various severities. Using time-series methods, the authors analyzed monthly frequencies of crash-induced injuries and fatalities from January 1978 through December 1987. Exposure to risk of occupant injury was controlled statistically by including aggregate frequency of crashes as a covariate in time-series models. Effects of economic conditions on traffic crashes were controlled by including an index of unemployment as a covariate. The following statistically significant effects were associated with the safety belt law: (a) In crashes with minor vehicle damage, there was a $14.6 \%$ reduction in B-level injuries, an $11.0 \%$ reduction in C-level injuries, and a $13.0 \%$ reduction in aggregate $(\mathrm{KABC}$ ) injuries; (b) in crashes with moderate vehicle damage, there was a $16.8 \%$ reduction in A-level injuries, an $11.6 \%$ reduction in B-level injuries, a $10.7 \%$ reduction in C-level injuries, and a $3.6 \%$ reduction in aggregate (KABC) injuries; (c) in crashes with severe vehicle damage, there was a $6.3 \%$ reduction in fatalities, an $11.8 \%$ reduction in B-level injuries, a $4.7 \%$ reduction in c-level injuries, and a $5.8 \%$ reduction in aggregate (KABC) injuries; (d) for all vehicle damage severities, there was a $14.0 \%$ reduction in $\mathrm{B}$-level injuries, an $8.3 \%$ reduction in C-level injuries, and a $6.4 \%$ reduction in injuries to front-seat occupants. Based on these results, Michigan's adult safety belt law has prevented 31,710 injuries from July 1985 through December 1988.
\end{abstract}

The state of Michigan mandated use of safety belts by drivers and front-seat passengers age 16 years and older beginning July 1985. The safety belt law permits secondary enforcement only. Several studies

Fredrick M. Streff, $\mathrm{PhD}$, is an assistant reasearch scientist and Robert $H$. Schultz is a research associate at The University of Michigan Transportation Research Institute (UMTRI). Alexander C. Wagenaar, $\mathrm{PhD}$, was an associate research scientist and head of the Injury Analysis and Prevention Group, UMTRI, at the time this paper was written. He is currently with the Marin Institute for the Prevention of Alcohol and Other Drug Problems.

The research reported here was supported in part by the Michigan Office of Highway Safety Planning and the U..S. Department of Transportation, National Highway Traffic Safety Administration. Findings and conclusions are solely have shown that compulsory belt use laws are effective in reducing fatalities caused by motor vehicle crashes (e.g., Campbell, 1988; Campbell, Stewart, \& Campbell, 1987; Chorba, Reinfurt, \& Hulka, 1988; Lund, Pollner, \& Williams, 1987; Partyka, 1988; Skinner \& Hoxie, 1988; Wagenaar, Maybee, \& Sullivan, 1988). However, published evaluations to date have not thoroughly examined in detail effects of belt use laws on the full range of nonfatal injuries.

Campbell (1988) examined effects of North Carolina's compulsory safety belt law on fatal, severe to fatal, and moderate to fatal injuries. North Carolina's law, which includes a primary enforcement provision, was implemented in two phases. In the first 15month phase, enforcement of the law was 
confined to oral or written warnings. The second phase included full enforcement with citations and a $\$ 25$ fine. Using time-series analyses, Campbell compared motor vehicle crash casualty figures from a 57-month baseline period to the 15 -month warningticket phase of the law. The warning-ticket phase resulted in no significant change in fatalities, a $6.9 \%$ decline $(p<.10)$ in serious to fatal injuries, and a $3.2 \%$ decline $(p<.10)$ in moderate to fatal injuries. Changes in frequencies of moderate or severe injuries alone were not reported. Campbell also compared the 72-month combined baseline and warning-ticket phases to the available 6 months of data for the full-enforcement phase. The full-enforcement phase resulted in an estimated $7.6 \%$ reduction in fatalities $(p=.10)$, a $13.6 \%$ reduction in serious to fatal injuries $(p<.01)$, and a $9.8 \%$ reduction in moderate to fatal injuries $(p<.01)$.

In a second study of the effects of North Carolina's safety belt use law, Chorba et al. (1988) found that the law was associated with significant reductions in injury. These researchers examined North Carolina State Police crash data, using tests for linear trends in proportions and chi-square analyses. Trend analyses showed that both the warning-ticket and full-enforcement phases resulted in significant decreasing trends in fatal and severe injuries among front-seat occupants and drivers, but no change in injuries among rear-seat occupants. Injury severity and frequency were stratified by vehicle damage severity and impact location. The warningticket period was found to be responsible for a significant decrease in the proportion of drivers who experienced fatal or severe injuries in nonfrontal crashes of medium severity. The proportion of right-front-seat occupants who experienced fatal or severe injuries in frontal crashes of medium severity also decreased compared to prelaw levels. Full enforcement resulted in significant decreases in the proportion of fatal or severe injuries suffered by drivers in frontal crashes of medium severity and in the proportion of fatal or severe injuries among front-seat occupants involved in severe frontal crashes and in nonfrontal crashes of medium severity.

The findings of Chorba et al. (1988) showed that the law was most effective in reducing injury in crashes of medium severity, reflecting the effectiveness of belts previously reported by Campbell (1987). Although previous evaluations of belt laws in the U.S. suggest that such laws are effective in reducing nonfatal injuries, separate analyses of minor, moderate, and severe injury severities have not been conducted. As a result, we examined effects of Michigan's belt law separately for minor, moderate, severe, and fatal injuries and stratified these injuries by crash severity.

Most evaluations have failed to control for effects that changing economic conditions have on traffic crashes. Several researchers (e.g., Evans \& Graham, 1987; Hoxie, Skinner, \& Wang, 1984; Joksch, 1984; Partyka, 1984; Wagenaar, 1984; Wagenaar \& Streff, 1989) have found that economic conditions can have a significant effect on casualties caused by traffic crashes. Typically, as economic conditions improve (measured by decreases in unemployment and increases in production indices, retail sales, and personal income), traffic casualties tend to increase. Precise mechanisms for this relationship have not yet been determined, and continued research is needed to fully understand these effects. Possible explanations for the relationship between improving economic conditions and increased traffic casualties may include increased travel (especially by teenagers, a high risk group), increased alcohol consumption away from home, and increased inclinations for risk-taking during periods of prosperity. It is unlikely that any one of these mechanisms alone is responsible for the observed relationship, and many other factors are probably involved. For the purpose of evaluating effects of belt use laws, it is sufficient to know that there is a relationship between economic indicators and traffic casualty rates and to control for economic effects statistically before assessing effects of a safety belt law.

\section{METHOD}

A monthly time-series design was used to control for numerous factors influencing the number of crash injuries and fatalities that were evident in multiyear trends, cycles, or 
other patterns. Analyses of the effects of the safety belt law were based on a prelaw baseline of 90 months (January 1978 through June 1985), and a postlaw pcriod of 30 months (July 1985 through December 1987). In addition, estimates of the law's effect on injuries to rear-seat and front-seat occupants were compared.

Data on injured occupants involved in motor vehicle crashes were obtained from the Michigan State Police. Records were obtained for all traffic crashes in the state of Michigan reported to local or state police agencies. Information was collected on vehicle damage severity, as well as occupant age, sex, and injury severity. Monthly fatality and injury totals were computed for occupants age 16 and over riding in passenger cars, vans, and light trucks. Injuries and fatalities involving ambulances, buses, specialized vehicles, and medium and heavy trucks were excluded because they are either exempt from the provisions of Michigan restraint laws or covercd by pre-cxisting laws or regulations. Data on monthly crash frequency and the rate of unemployment were used to control for other changes influencing injury and fatality rates during the 1978-1987 period examined. Monthly rates of unemployment among noninstitutionalized Michigan residents age 16 and over were obtained from the U.S. Bureau of Labor Statistics.

Our goal was to estimate shifts in each injury and fatality time series associated with implementation of the adult safety belt law in July 1985. Methods of Box and Jenkins (1976) were employed to control for longterm trends and seasonal cycles, and intervention models (Box \& Tiao, 1975) were used to estimate any changes beginning the

FIGURE 1

EFFECTS OF MICHIGAN'S SAFETY BELT LAW ON INJURY AND FATALITY FREQUENCIES FOR ALL CRASHES: POINT ESTIMATES AND 95\% CONFIDENCE INTERVALS

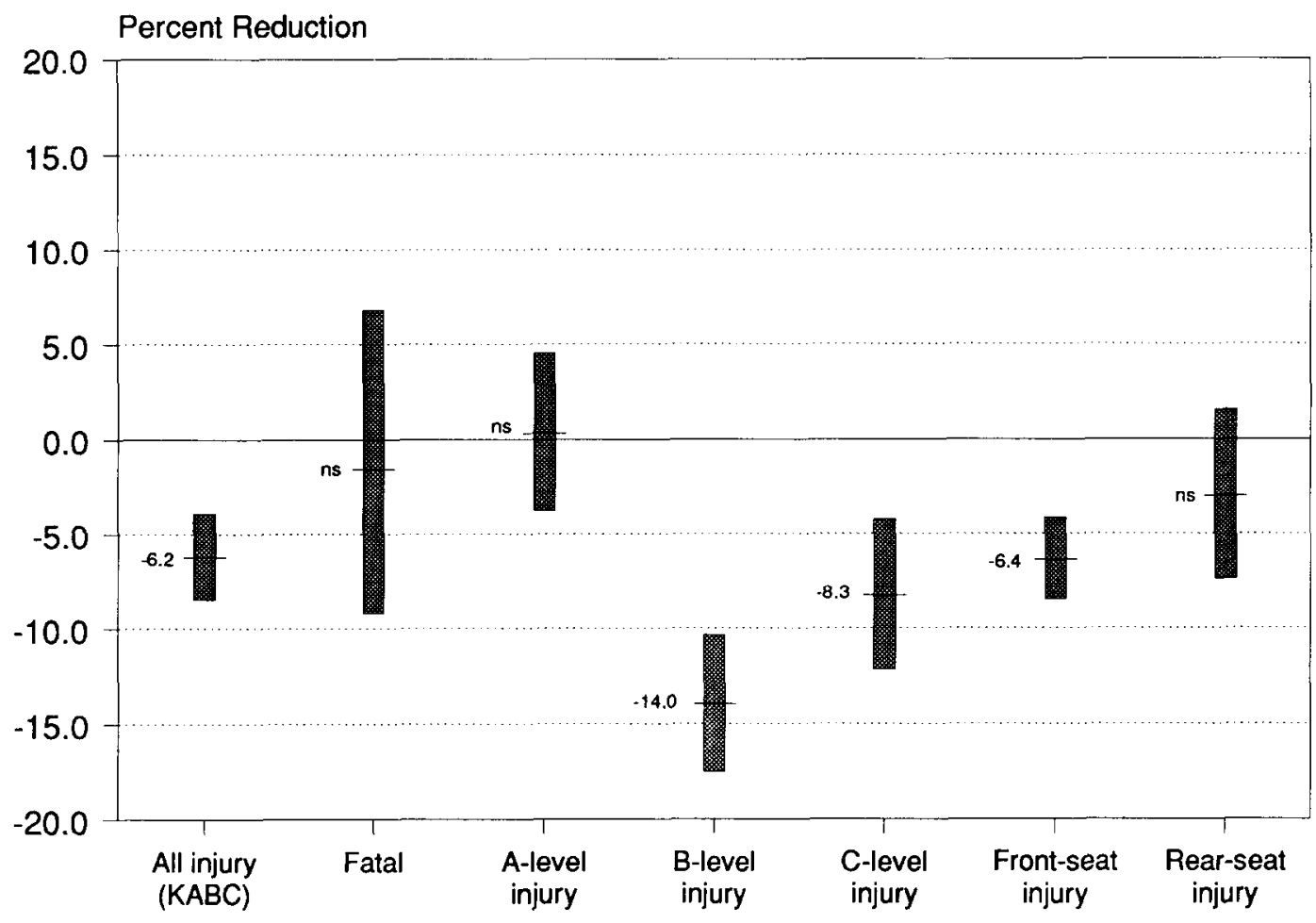

ns = not statistically significant at $0<.05$ 
TABLE 1

EFFECTS OF MICHIGAN'S SAFETY BELT LAW ON INJURY AND FATALITY

FREQUENCIES: TIME-SERIES MODEL ESTIMATES

\begin{tabular}{|c|c|c|c|c|c|c|}
\hline \multirow[b]{2}{*}{$\begin{array}{l}\text { Injury } \\
\text { Category }\end{array}$} & \multirow[b]{2}{*}{ Model Paraneter } & \multirow[b]{2}{*}{ Estimate } & \multirow[b]{2}{*}{$\begin{array}{l}\text { Standard } \\
\text { Error }\end{array}$} & \multirow[b]{2}{*}{$\stackrel{x}{\text { Change }}$} & \multicolumn{2}{|c|}{$95 x$ Confidence Interval } \\
\hline & & & & & Low & High \\
\hline $\begin{array}{l}\text { Al1 injury } \\
\text { (KABC) }\end{array}$ & $\begin{array}{l}\text { Belt law effect } \\
\text { Crash frequency lag } 0 \\
\text { Unemployment rate lag } 0 \\
\qquad \text { ARIMA }(0,0\end{array}$ & $\begin{array}{r}-.0645 \\
.6100 \\
-.0568 \\
(0,1,1)\end{array}$ & $\begin{array}{r}.0919 \\
.0339 \\
.0219 \\
\text { usted } R^{2}\end{array}$ & $\begin{array}{l}-6.25^{\star} \\
505\end{array}$ & -4.03 & -8.41 \\
\hline Fatal injury & $\begin{array}{l}\text { Belt law effect } \\
\text { Crash frequency lag } 0 \\
\text { Unempl oyment rate lag } 1 \\
\text { Unempl oyment rate lag } 4 \\
\text { Unemployment rate lag } 6 \\
\text { ARIMA }(0,0\end{array}$ & $\begin{array}{r}-.0155 \\
-.2360 \\
.2128 \\
-.3729 \\
-.3192 \\
(0,1,1)\end{array}$ & $\begin{array}{r}.0453 \\
.1471 \\
.1372 \\
.1892 \\
.1495 \\
\text { usted } R^{2}\end{array}$ & $\begin{array}{l}-1.54 \\
528\end{array}$ & 6.77 & -9.19 \\
\hline Severe injury & $\begin{array}{l}\text { Belt law effect } \\
\text { Crash frequency lag } 0 \\
\text { Unemploment rate lag } 1 \\
\text { ARIMA }(0,0\end{array}$ & $\begin{array}{r}.0030 \\
.3118 \\
-.2122 \\
(0,1,1)_{1}\end{array}$ & $\begin{array}{r}.0211 \\
.0626 \\
.0384 \\
\text { usted } R^{2}\end{array}$ & $\begin{array}{r}0.30 \\
539\end{array}$ & 4.54 & -3.76 \\
\hline $\begin{array}{l}\text { Moderate } \\
\text { injury }\end{array}$ & $\begin{array}{l}\text { Beit law effect } \\
\text { Crash frequency lag } 0 \\
\text { Unemployment rate lag } 5 \\
\text { ARIMA }(0,0\end{array}$ & $\begin{array}{r}-.1506 \\
.3648 \\
-.1858 \\
(0,1,1)_{1}\end{array}$ & $\begin{array}{r}.0211 \\
.0484 \\
.0351 \\
\text { usted } R^{2}\end{array}$ & $\begin{array}{l}-13.98 * \\
004\end{array}$ & -10.35 & -17.47 \\
\hline Minor injury & $\begin{array}{l}\text { Belt law effect } \\
\text { Crash frequency lag } 0 \\
\text { Unemployment rate lag } 2 \\
\text { Unempl ayment rate lag } 3 \\
\text { Unempl ayment rate lag } 4 \\
\text { Unemployment rate lag } 5 \\
\text { ARIMA } 10,1\end{array}$ & $\begin{array}{r}-.0864 \\
.7634 \\
.0439 \\
-.0531 \\
.0613 \\
-.0689 \\
(0,1,1)_{1}\end{array}$ & $\begin{array}{r}.0220 \\
.0351 \\
.0425 \\
.0515 \\
.0499 \\
.0430 \\
\text { usted } R^{2}\end{array}$ & $-8.28^{\star}$ & -4.23 & -12.15 \\
\hline $\begin{array}{l}\text { Front-seat } \\
\text { occupant } \\
\text { injury }\end{array}$ & $\begin{array}{l}\text { Belt law effect } \\
\text { Crash frequency lag } 0 \\
\text { Unemployment rate lag } 0 \\
\text { ARIMA } 0,0\end{array}$ & $\begin{array}{r}-.0656 \\
.6233 \\
-.0576 \\
(0,1,1)_{1}\end{array}$ & $\begin{array}{r}.0118 \\
.0339 \\
.0219 \\
\text { usted } R^{2}\end{array}$ & $\begin{array}{l}-6.35^{\star} \\
527\end{array}$ & -4.16 & -8.49 \\
\hline $\begin{array}{l}\text { Rear-seat } \\
\text { occupant } \\
\text { injury }\end{array}$ & $\begin{array}{l}\text { Belt law effect } \\
\text { Crash frequency lag } 0 \\
\text { Unempl oyment rate lag } 0 \\
\text { Unempl oyment rate lag } 2 \\
\text { Unempl oyment rate lag } 5 \\
\text { ARIMA }(0,0\end{array}$ & $\begin{array}{r}-.0307 \\
.4195 \\
-.1224 \\
.1919 \\
-.1619 \\
(0,1,1)\end{array}$ & $\begin{array}{l}.0233 \\
.0788 \\
.0838 \\
.0934 \\
.0695 \\
\text { sted } R^{2}\end{array}$ & -3.02 & 1.51 & -7.35 \\
\hline
\end{tabular}

${ }^{\star} \mathrm{Q}<.05$. 
FIGURE 2

EFFECTS OF MICHIGAN'S SAFETY BELT LAW ON INJURY AND FATALITY FREQUENCIES BY CRASH SEVERITY: POINT ESTIMATES AND 95\% CONFIDENCE INTERVALS

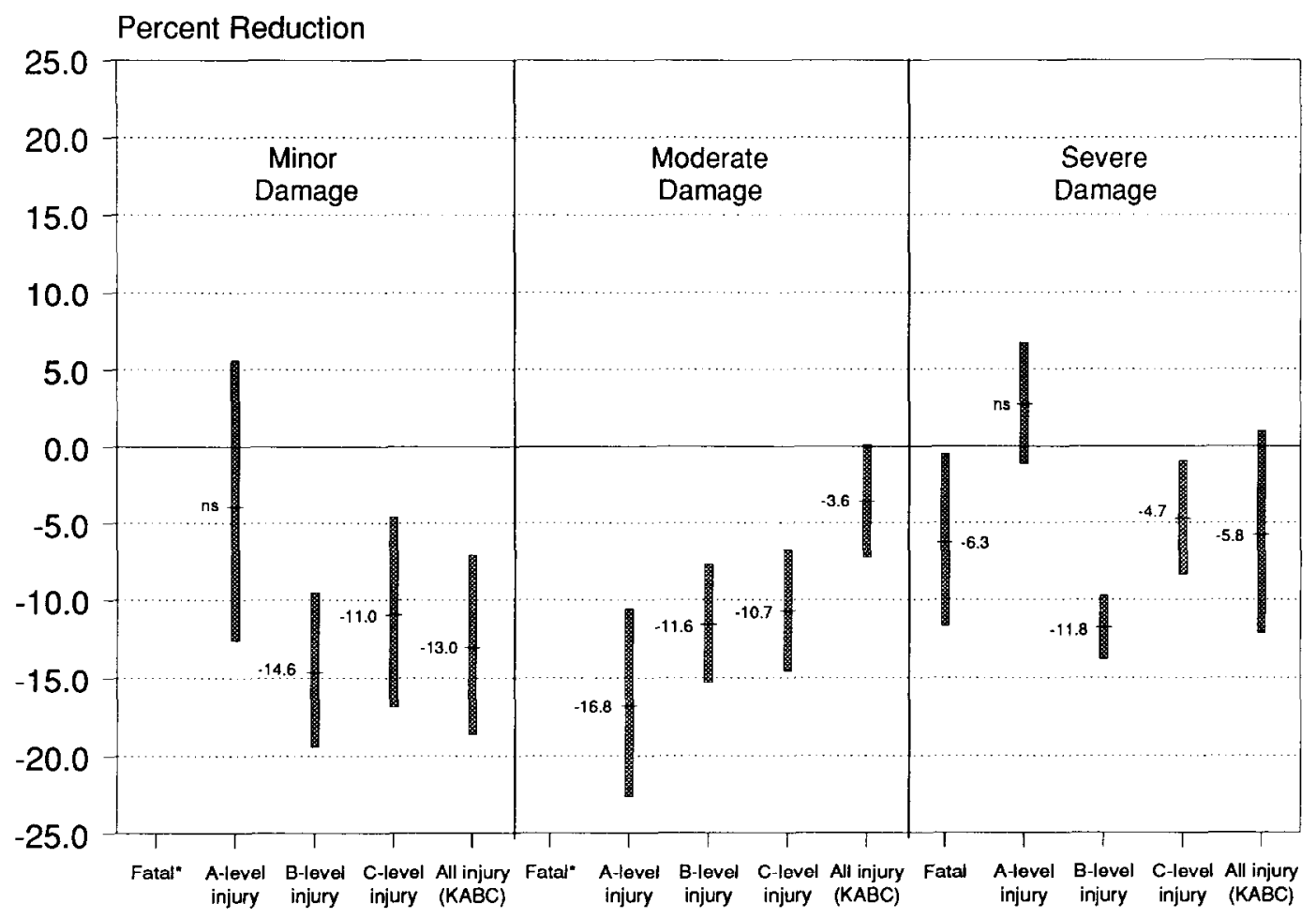

ns $=$ not statistically significant at $p<.05$

*- insutficient sample size for time-series analysis

first month the law took effect. At a conceptual level, the analytic strategy involves explaining as much of the variance in each variable as possible on the basis of its own past history, before attributing any of the variance to another variable, such as passage of a law making restraint use compulsory. The intervention-analysis approach is particularly appropriate for the present study, because the objective was to identify significant shifts in injury and fatality frequencies associated with the belt law, independent of observed regularities in the history of each variable. In short, controlling for baseline trends and cycles with time-series models produces more accurate estimates of the effects of legislation mandating restraint use.

Injury reductions associated with the adult belt law were examined for each level of injury severity, using the "KABC" injury severity scale. K-level injuries are injuries that were caused by the crash and that resulted in death within 90 days of the incident. Alevel injuries are incapacitating injuries that prevent injured persons from continuing activities they were capable of performing prior to the injury. B-level injuries include nonincapacitating injuries that are evident to observers at the scene of the crash in which the injury occurred. C-level injuries are possible injuries reported or claimed, but which are not fatal, incapacitating, or nonincapacitating evident injuries (National Safety Council, 1984). Although more precise injury severity scoring would be desirable for examining effects of the belt law (e.g., the Abbreviated Injury Scale, American 
TABLE 2

EFFECTS OF MICHIGAN'S SAFETY BELT LAW ON INJURY AND FATALITY FREQUENCIES BY CRASH SEVERITY: TIME-SERIES MODEL ESTIMATES

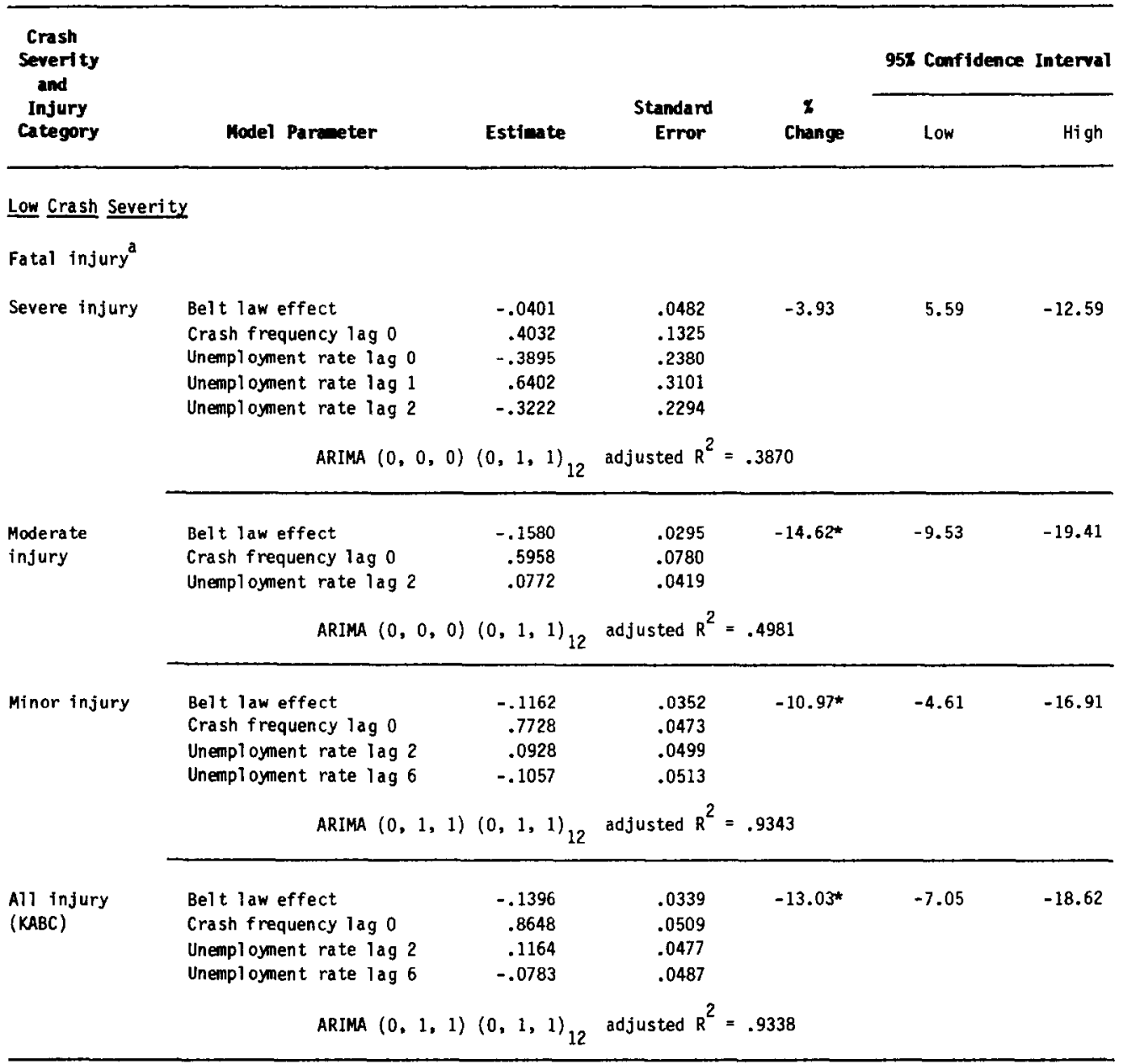

Medium Crash Severity

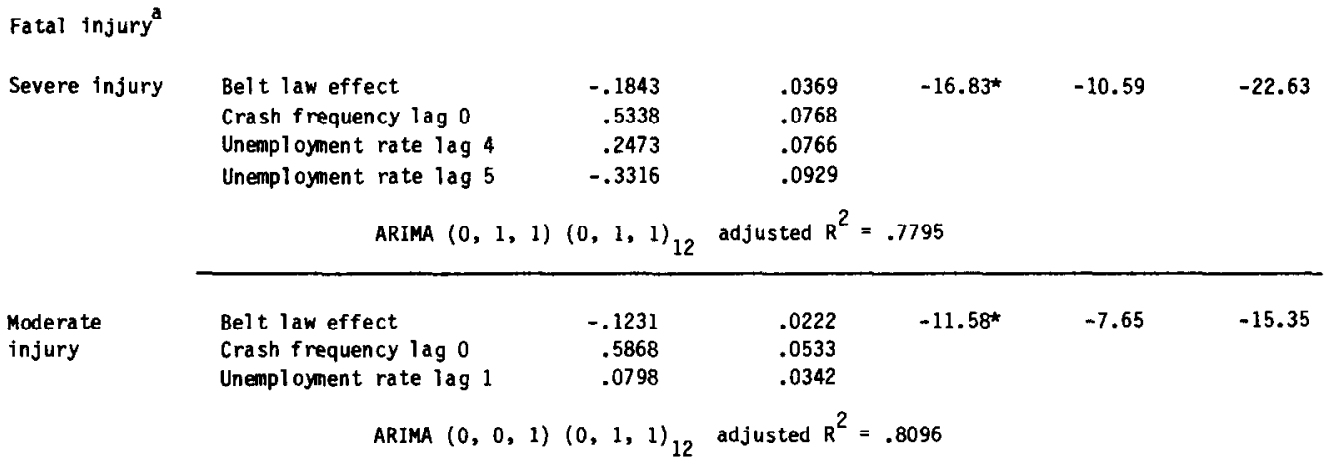




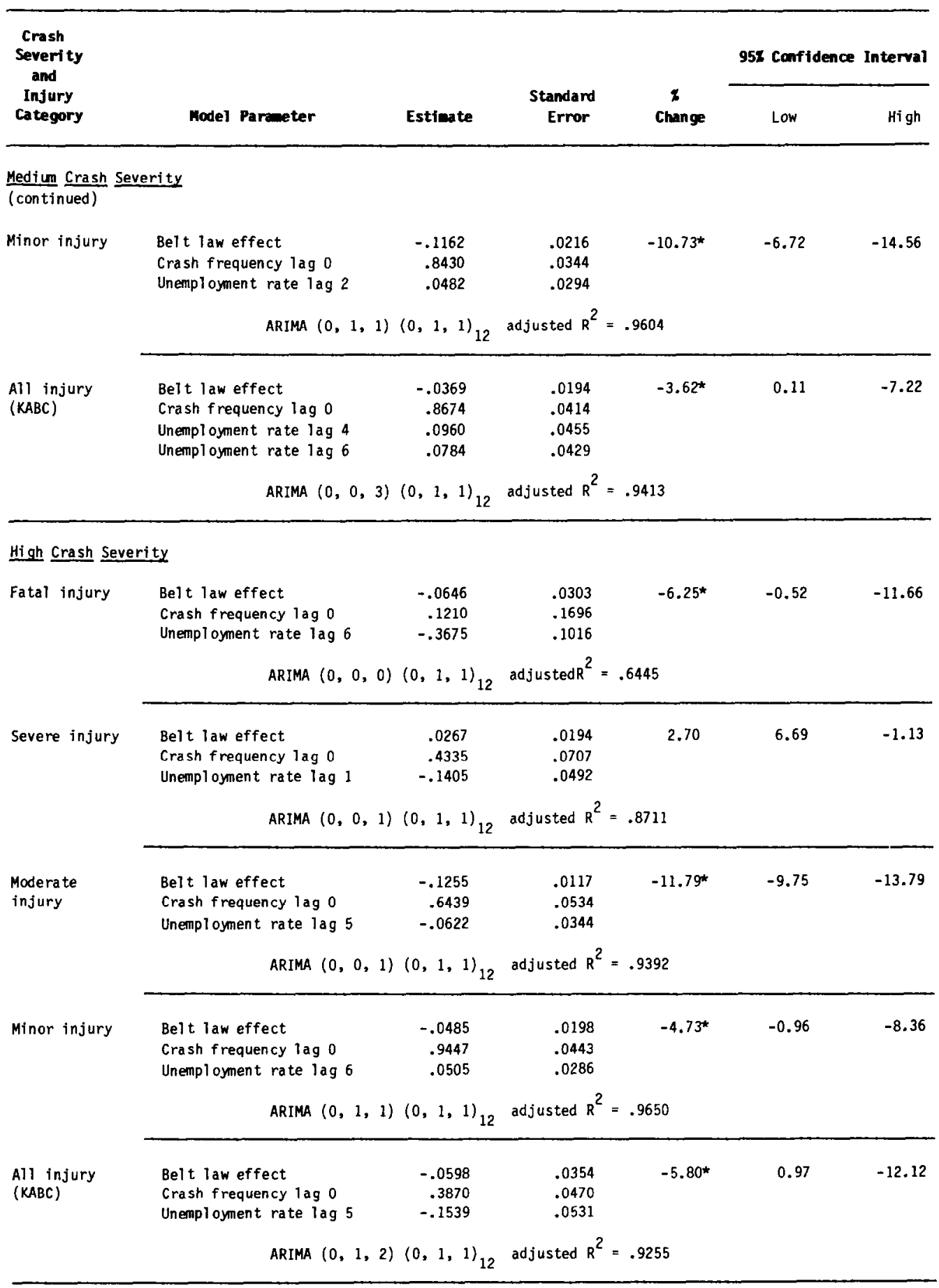

${ }^{\star} \underline{p}<.05 .{ }^{\text {a }}$ Insufficient sample size for time-series analysis. 
TABLE 3

ANNUAL PROJECTED SAVINGS FROM MICHIGAN'S SAFETY BELT LAW

\begin{tabular}{lcc}
\hline $\begin{array}{c}\text { Injury } \\
\text { Category }\end{array}$ & $\begin{array}{c}\text { Injuries } \\
\text { Prevented }\end{array}$ & Cost \\
\hline Fatal & 66 & $\$ 99,000,000$ \\
A-level & 494 & $19,266,000$ \\
B-level & 4,244 & $50,928,000$ \\
C-level & 4,256 & $27,527,808$ \\
\hline Annual savings & 9,060 & $194,730,000$ \\
\hline
\end{tabular}

Association for Automotive Medicine, 1985), such data were not available from police crash reports.

Safety belt use laws are expected to affect injury once a crash has occurred, but not to affect the number of crashes. Therefore, we controlled for exposure to the risk of injury by including monthly aggregate crash frequency as a covariate in the time-series models. In addition to controlling for the risk of injury, we also included an index of unemployment to statistically control for the effects of changing economic conditions on traffic crashes.

Effects of the safety belt law on injury were examined separately for crashes of various levels of vehicle damage severity. Crash damage severity was divided into three groups using the Traffic Accident Damage (TAD, National Safety Council, 1971) scale: minor (TAD levels 1 and 2), moderate (TAD levels 3 and 4 ), and severe (TAD levels 5 through 8). TAD scale estimates are made by police at the site of the crash and are determined by the extent of vehicle deformation caused by the crash.

\section{RESULTS}

\section{Estimated Reductions in Injury and Fatality Frequencies}

Michigan's safety belt law was effective in 16 reducing motor vehicle crash casualties. Overall, there was a $6.2 \%$ reduction in injury to vehicle occupants associated with the safety belt law (Figure 1, Table 1). This figure includes fatal, A-level, B-level, and C-level injuries to vehicle occupants, regardless of thcir seating position and crash scverity. There was a $6.4 \%$ overall reduction in injuries to front-seat occupants associated with the law. No significant reduction in injury was found for rear-seat occupants, supporting the conclusion that the observed injury reduction was caused by the implementation of the safety belt law. When effects of the belt law on specific injury severity levels were examined without separating effects of differing crash severity, there was no significant change detected in fatal or severe injury frequencies. However, there was a $14.0 \%$ reduction in moderate injuries and an $8.3 \%$ reduction in minor injuries associated with the belt law.

Injury reductions associated with the safety belt law differed by crash damage severity (see Figure 2, Table 2). A $6.3 \%$ reduction in fatal injuries in high-severity crashes (high vehicle damage) was associated with the law. Small monthly frequencies of fatal crashes involving minor and moderate vehicle damage precluded analysis of effects of the belt law on fatalities in those crashes. A $16.8 \%$ reduction in A-level injuries in crashes of moderate severity (moderate vehicle damage) was associated with the law; however, there was no statistically significant change in A-level injury frequency in minor or severe crashes. This is consistent with the findings of Campbell (1987) and Chorba et al. (1988). Significant B-level and C-level injury reductions are associated with the law for each crash damage severity group.

\section{Economic Benefits from Restraint Laws}

Recent studies have proposed alternative approaches to valuing the injury and loss of life resulting from traffic crashes. Kragh, Miller, and Reinert (1986) compared current approaches to calculating injury costs. They suggest the willingness-to-pay method best represents the totality of costs related to traffic injuries and death. This method involves an assessment of several cost categories: (a) 
consumption goods (i.e., goods and services not used during the remaining lifetime); (b) human capital costs (loss of ability to perform vocational and avocational work); (c) psychosocial and quality of life costs (mental anguish, drug abuse, family problems, missed opportunities, loss of contact with friends/community); and (d) value placed on life and safety (money, time, freedom, and other measures of what one is willing to pay to reduce injuries). Miller, Luchter, and Brinkman (1989) suggest that agencies use the willingness-to-pay approach to estimate rational investment levels to pay for increases in safety and health. The U.S. Department of Transportation estimates willingness-to-pay costs to be (in 1986 dollars): $\$ 1.5$ million for each fatal injury, $\$ 39,000$ for each A-level injury, $\$ 12,000$ for each B-level injury, and $\$ 6,000$ for each C-level injury (Federal Highway Administration, 1988).

The value placed on life and safety estimated by the willingness-to-pay approach is based on reductions in probabilities of future events rather than valuing injuries and deaths which have already occurred. Based on the estimated injury reductions from our analyses, we project that 9,060 injuries are prevented annually because of Michigan's safety belt law (Table 3). Based on the willingness-to-pay cost estimation method, it would be reasonable to invest over $\$ 194$ million annually to prevent these injuries. This acceptable level of investment is far greater than the actual costs associated with promoting and maintaining the belt law. The Michigan State Police Office of Highway Safety Planning has spent an average of $\$ 628,192$ each year to support the law (including public information and education campaigns, funding for increased belt law enforcement, and sponsorship of other special safety belt use promotion projects) since the implementation of the law.

\section{DISCUSSION}

Significant reductions in each level of injury severity were associated with the safety belt law, however, the magnitude of these reductions differed by crash severity. The belt law appears to have been more effective in reducing moderate and minor injuries than severe or fatal injuries. There was no significant effect associated with the belt law for fatal and severe injuries, with the exception of significant decreases in fatal injuries in high-severity crashes and severe injuries in medium-severity crashes. Moderate and minor injuries were found to decrease in the aggregate as well as in each level of crash severity. Although costs associated with fatal and severe injury are higher than those of moderate and minor injury, a larger proportion of all motor vehicle crash injury occurs at moderate and minor injury levels. Thus, significant reductions in moderate and minor injury have important implications for public health and economic well-being. The value associated with the prevention of 8,500 moderate or minor injuries in Michigan each year resulting from the belt use law is over $\$ 75$ million.

Our results show that it is valuable to analyze belt law effects by crash severity. Analyses of the aggregate injury data suggest there was no effect of the belt law on fatal or severe injuries. However, when examined by crash severity, significant declines were detected in fatal injuries in crashes of high severity and in severe injuries in crashes of medium severity. Had the data not been analyzed by crash severity, these important effects would have gone undetected, thus understating the effects of the belt law. The $6.3 \%$ reduction in fatal injuries in high severity crashes and the $16.8 \%$ reduction in severe injuries in crashes of medium severity prevent 66 deaths and nearly 500 serious injuries each year in Michigan.

Although Michigan's belt law has been effective in reducing both fatal and nonfatal motor vehicle crash injuries, some critics contend that it has not produced the injury reductions that were originally suggested by proponents of the law. This does not appear to be true. Based on annual roadside observation studies of belt use at a probability sample of 240 intersections throughout Michigan, belt use increased from about $20 \%$ prior to the law to $45 \%$ following its implementation (Wagenaar \& Molnar, 1989). Using the approach of Evans (1986), observed increases in belt use in Michigan should reduce fatalities by $9.2 \%$ to $11.7 \%$. Although our point estimate of a $6.3 \%$ decline in fatal 
injuries is slightly lower than these projected effects, the confidence band of the estimate is within the range of expected effects.

\section{REFERENCES}

American Association for Automotive Medicine. (1985). The abbreviated injury scale . (1985 revision). Arlington Heights, IL: Author.

Box, G. E. P. \& Jenkins, G. M. (1976). Time series analysis: Forecasting and control (Rev, ed.). San Francisco: Holden-Day.

Box, G. E. P. \& Tiao, G. C. (1975). Intervention analysis with applications to economic and environmental problems. Journal of the American Statistical Association, 70, 70-79.

Campbell, B. J. (1987). Safety belt injury reduction related to crash severity and front-seated position. Journal of Trauma, 27, 733-739.

Campbell, B. J. (1988). North Carolina's seat belt law: Public safety and public policy. Popular Government, 53(3), 27-35.

Campbell, B. J., Stewart, J. R., \& Campbell, F. A. (1987). 1985-1986 Experience with seat belt laws in the United States. Chapel Hill, N.C.: The University of North Carolina Highway Safety Research Center.

Chorba, T.L., Reinfurt, D., \& Hulka, B.S. (1988). Efficacy of mandatory seat-belt use legislation. Journal of the American Medical Association, 260, 3593-3597.

Evans, L. (1986), Estimating fatality reductions from increased safety belt use (Report No. GMR-5420). Warren, MI: General Motors Research Laboratory.

Evans, W. \& Graham, J. D. (1987). Traffic fatalities and the business cycle. Boston,MA: New England Injury Prevention Research Center.

Federal Highway Administration. (1988). Motor vehicle accident costs. (Technical Advisory T 7570.1).

Washington, D.C.: U.S. Department of Transportation, Federal Highway Administration.

Hoxie, P., Skinner, D., \& Wang, G. H. (1984). Socioeconomic influences on highway fatalities: An empirical investigation. (Report No. DOT-TSC-NHTSA84-1). Washington, D.C.: U.S. Department of Transportation, National Highway Traffic Safety Administration, Office of Research and Development.
Joksch, H. C. (1984). The relation between motor vehicle accidents and economic activity. Accident Analysis and Prevention, I6, 207-210.

Kragh, B. C., Miller, T. R., \& Reinert, K. A. (1986). Accident costs for highway safety decision making Public Roads, 50, 15-20.

Lund, A. K., Pollner, J., \& Williams, A. F. (1987). Preliminary estimates of the effects ofmandatory seat belt use laws. Accident Analysis and Prevention, 19, 219-222.

Miller, T. R., Luchter, S.,\& Brinkman, C. P. (1989). Crash costs and safety investment.Accident Analysis and Prevention, 21, 303-315.

National Safety Council. (1971). Vehicle damage scale for traffic accident investigators. (2nd ed.) Chicago, IL: Author.

National Safety Council. (1984). Manual on classification of motor vehicle accidents.(4th ed.) Chicago, IL: Author.

Partyka, S. C. (1984). Simple models of fatality trends using unemployment and population data. Accident Analysis and Prevention, 16, 211-222.

Partyka, S.C. (1988). Lives saved by seat belts from 1983 through 1987. Washington, D.C.: Mathematical Analysis Division, National Center for Statistics and Analysis.

Skinner, D. and Hoxie, P. (1988). Effects of sealbell laws on highway fatalities. (Project memorandum - DOT-TSC-HS870-PM-88-5). Washington, D.C.: U.S. Department of Transportation, National Highway Traffic Safety Administration.

Wagenaar, A. C. (1984). Effects of macroeconomic conditions on the incidence of motor vehicle accidents. Accident Analysis and Prevention, 16, 191-205.

Wagenaar, A. C., Maybee, R. G., and Sullivan, K .P. (1988). Mandatory seat belt laws in eight states: A timeseries evaluation. Journal of Safety Research, 19, 51-70.

Wagenaar, A.C., and Molnar, L.J., (1989). Direct observation of seat belt use in Michigan: Spring 1989. Ann Arbor: The University of Michigan Transportation Research Institute.

Wagenaar, A. C., and Streff, F. M. (1989). Macroeconomic conditions and alcohol-impaireddriving. Journal of Studies on Alcohol, 50, 217-225. 